\title{
Epidemiological Risk Factors Associated with Acne Vulgaris Presentation, Severity, and Scarring in a Singapore Chinese Population: A Cross-Sectional Study
}

\author{
Anna Hwee Sing Heng Yee-How Say Yang Yie Sio Yu Ting Ng Fook Tim Chew \\ Department of Biological Sciences, National University of Singapore, Singapore, Singapore
}

\section{Keywords}

Acne vulgaris · Acne severity · Acne scarring · Epidemiology · Risk factors

\begin{abstract}
Background: Acne vulgaris is classified based on the severity of skin lesions and post-healing scar types of these lesions. Numerous epidemiology studies have investigated the risk factors associated with acne presentation and severity, but studies for acne scarring are lacking. Objective: To investigate the prevalence of acne, severity, and scarring grades and their associated risk factors among Singapore Chinese. Methods: A total of 3,888 subjects $(2,090$ cases $/ 1,798$ controls; median age $=21 \pm 4.589$; range $17-71$ ) completed an investigator-administered questionnaire as part of a cross-sectional study, which included sociodemographics, familial medical history, lifestyle factors, dietary habits, and acne history. Acne cases were further evaluated for their severity $(n=991)$ and scarring $(n=988)$ grades by a trained personnel. Results: The majority of the acne cases had mild acne/grade 1 scarring, while less than $1 \%$ had severe acne/grade 4 scarring. Parental acne was significantly associated with acne presentation and moderate/severe
\end{abstract}

karger@karger.com www.karger.com/drm

Karger"

GOPEN ACCESS
(C) 2021 The Author(s)

Published by S. Karger AG, Basel

This is an Open Access article licensed under the Creative Commons Attribution-NonCommercial-4.0 International License (CC BY-NC) (http://www.karger.com/Services/OpenAccessLicense), applicable to the online version of the article only. Usage and distribution for commercial purposes requires written permission. acne, while sibling acne was significantly associated with grade 3/4 scarring. Gender and age affected acne severity and scarring but not acne presentation, while tertiary maternal education level and the possession of $\geq 3$ siblings were particularly associated with acne scarring. Underweight BMI was protective against acne presentation, while atopic diseases (asthma, allergic rhinitis, eczema) were its predisposing factors. Of the evaluated lifestyle factors, computer/TV usage had significant association with acne presentation, while alcohol consumption was significantly associated with acne severity. Frequent milk consumption was associated with a protective effect for moderate-severe acne, while frequent butter consumption had a detrimental effect on acne scarring extent. Conclusion: Positive familial history is a strong predisposing factor in determining acne presentation, severity, and scarring. Demographic factors (gender, age) and sedentary lifestyle (increased computer/TV usage) influence acne presentation, while dietary habits (milk and butter consumption) influence acne severity and scarring. The predisposing factors revealed in this study could help us to gain insights into acne pathophysiology and hence develop interventions especially targeting modifiable risk factors.

(c) 2021 The Author(s)

Published by S. Karger AG, Basel

Correspondence to:

Fook Tim Chew, dbscft@nus.edu.sg 


\section{Introduction}

Acne vulgaris (hereby acne) is an inflammatory skin condition that is well characterised clinically [1]. The pilosebaceous unit is well known as the site for acne development. It is comprised of the hair follicle and sebaceous gland, which produces and secretes sebum onto the skin surface via the pore of the hair follicle [2]. Acne lesions develop when the pore of the pilosebaceous unit is blocked or inflamed [3].

Acne lesions can be classified into a few types - comedones, papules, pustules, nodules, and cysts - based on their size and appearance [2]. Comedones are often referred to as "non-inflammatory lesions" while papules, pustules, nodules, and cysts are collectively termed as "inflammatory lesions" due to their red and swollen appearance [3]. Based on the acne lesions that an individual present, their acne severity can be broadly classified into three categories mild, moderate, and severe; milder acne presents with noninflammatory lesions while more severe acne presents with both inflammatory and non-inflammatory lesions [3]. During the healing process of acne lesions, the damaged skin may develop scars [4]. The two basic scar types - depending on whether there is a net loss or gain of collagen - are atrophic (majority of scars) and hypertrophic scars and keloids (minority) [5]. Several classifications and scales of scarring have been proposed: Goodman and Baron $[6,7]$ proposed a qualitative scale and then presented a quantitative scale, while Dreno et al. [8] introduced the ECCA scale (Echelle d'Evaluation Clinique des Cicatrices d'Acné).

Recently, we reviewed that epidemiological risk factors influencing acne presentation and severity include demographic, genetic and hormonal, dietary, and personal factors; familial history, age, BMI, and skin type stood out as the strongest factors [9]. While many epidemiology studies have investigated the risk factors for acne presentation, fewer studies have specifically studied the risk factors for acne severity and acne scarring. To the best of our knowledge, only two studies were conducted in Singapore in 2007; both evaluated acne severity and only studied psychosocial factors affecting acne among teenagers $[10,11]$. Therefore, this study investigated the prevalence of acne, acne severity, and scarring grades, and their associated epidemiological risk factors among a cohort of the Singapore Chinese population.

\section{Materials and Methods}

For further details, see the supplementary material available online at www.karger.com/doi/10.1159/000516232 (Fig. 1).

\section{Results}

Prevalence of Acne, Acne Severity Grades, and Acne Scarring Grades

Data obtained from 3,888 subjects $(\mathrm{M} / \mathrm{F}=1: 1.23)$ was analysed and the distribution of their demographic and socioeconomic characteristics is described in Table 1 . The age range of participants was 17-71 years (median $=21$, $\mathrm{SD}=4.589$ ). The overall prevalence of acne was $53.8 \%$, with females outnumbering males. There was no significant difference in acne case/control distribution between genders $\left(\chi^{2}=0.211 ; p=0.646\right)$, age groups $\left(\chi^{2}=2.7 ; p=\right.$ $0.259)$, or family income levels $\left(\chi^{2}=1.362 ; p=0.714\right)$. The majority of the acne cases had mild acne or no current/ grade 1 scarring, while less than $1 \%$ had severe acne or grade 4 scarring (Table 1 ).

\section{Risk Factors That Showed Significant Differences \\ between Acne Cases and Controls}

The risk factors that were significantly associated with acne presentation are presented in Table 2 . A positive familial history of acne was strongly associated with an increased risk for acne presentation, even after controlling for age, gender, family monthly household income, BMI, smoking status, alcohol drinking habit, and physical activity. Acne was more frequently observed in individuals whose mother, father, or sibling had acne history compared to those without; higher odds were seen for paternal history than maternal or sibling history (Table 2). When maternal and paternal familial history were combined, the adjusted odds ratio (OR) for acne presentation was 2.565 and 2.487, for those with one and both parents with acne history, respectively; suggesting that maternal and paternal acne do not show additive effects. Similarly, when maternal, paternal, and sibling acne history were combined, an additive effect was not observed.

Presentation of certain comorbidities was also found to be associated with acne presentation (Table 2). BMI was associated with acne presentation, with underweight $\mathrm{BMI}$ as a protective factor for acne (adjusted $\mathrm{OR}=0.820$; Table 2). This association became marginally insignificant after addition of familial history in adjustment for confounding factors $(\mathrm{OR}=0.819,95 \% \mathrm{CI}$ : 0.669-1.004, $p=0.055$ ), suggesting that the protective effect may be dependent of familial history. Acne was also more frequently observed in those with other comorbidities - atopy, asthma, allergic rhinitis, eczema, polycystic ovarian syndrome (PCOS), or at least one atopic disease (which includes allergic rhinitis, asthma, or eczema; Table 2). After further adjustment for familial history, higher acne 


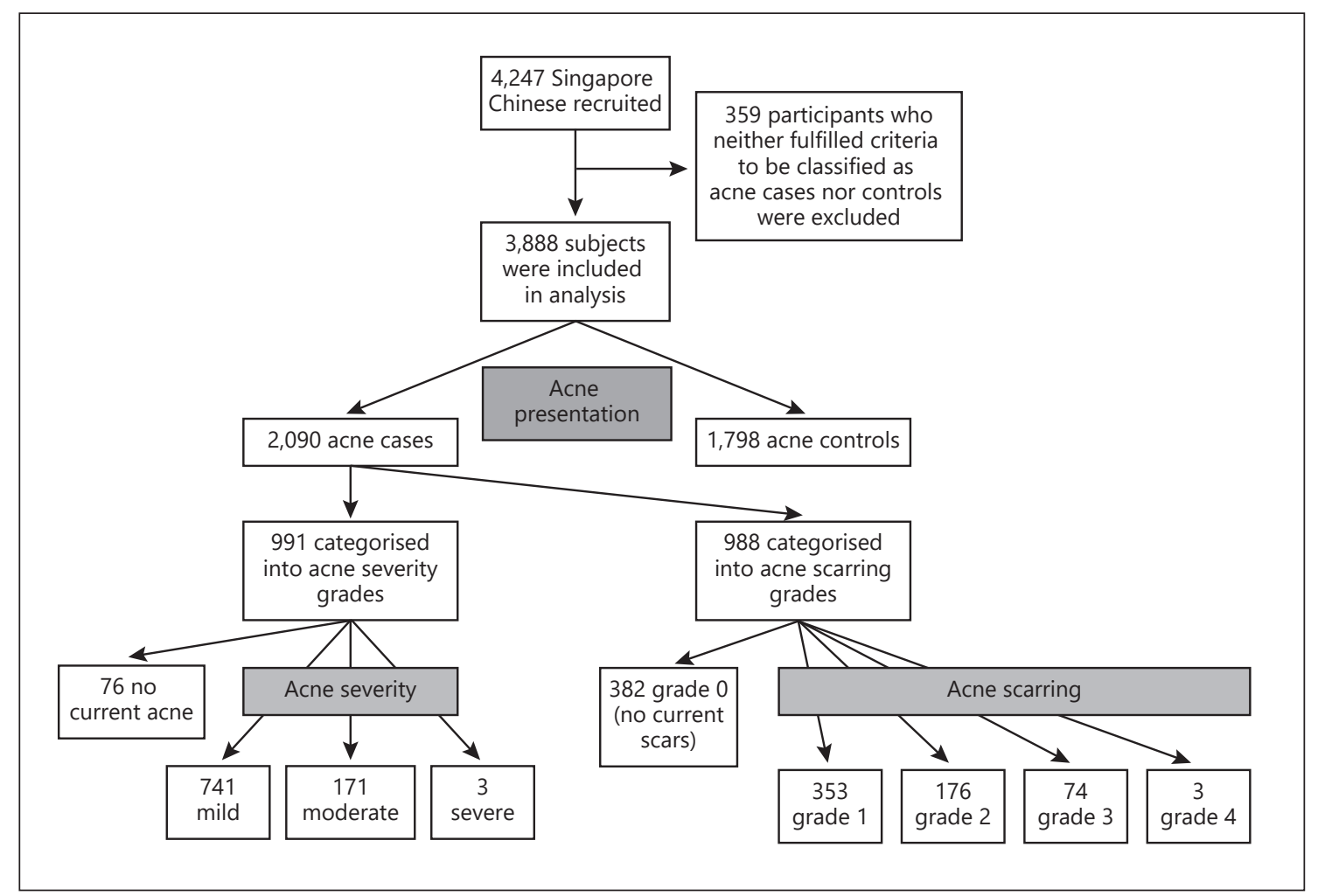

Fig. 1. Flowchart of Materials and Methods: subject recruitment and acne presentation, severity, and scarring subsets.

prevalence was still observed in those with eczema $(\mathrm{OR}=$ 1.323, 95\% CI: $1.085-1.614, p=0.006)$ and PCOS (OR = $2.387,95 \%$ CI: $1.024-5.565, p=0.044)$, suggesting that the genetic components that predispose individuals to acne may be independent of those that predispose individuals to eczema and PCOS.

Furthermore, acne presentation was significantly associated with a sedentary lifestyle, which was evaluated based on the number of hours subjects watched TV and/ or used the computer per day (Table 2). Acne was significantly associated with those who used the computer/ $\mathrm{TV}>3 \mathrm{~h}$ per day (Table 2). After adjustment for familial history, the significance still remained: usage $3-5 \mathrm{~h}$ per day $(\mathrm{OR}=1.573,95 \% \mathrm{CI}: 1.207-2.049, p=0.001)$, usage $>5 \mathrm{~h}$ per day $(\mathrm{OR}=1.395,95 \% \mathrm{CI}: 1.065-1.828, p=0.016)$, relative to those who did that for $<1 \mathrm{~h}$ per day. This suggests that sedentary lifestyle is independently associated with acne presentation over and above familial history.

Aside from the above, no significant association with acne presentation was observed for other evaluated factors, including all lifestyle factors (like smoking, alcohol-drinking, and physical activity) and dietary habits (like meat, dairy, fruits, vegetables, fast food, probiotic consumption).
Risk Factors That Showed Significant Differences between Higher Grades (Moderate/Severe and Grade 3/4) and Milder Grades (Mild and Grade 1/2) of Acne Severity and Scarring

Male gender was a predisposing factor moderate/severe and grade $3 / 4$ acne, even after controlling for confounding factors (Table 3 ). Age only had a significant effect on acne severity grade, where those $\leq 19$ years had higher odds of having moderate/severe acne, compared to those $>24$. Out of all other evaluated sociodemographic factors, only maternal education level and number of siblings were significantly associated with acne scarring extent (Table 3).

Similar with acne presentation, sibling history was associated with more severe acne scars relative to milder acne scars, while combined maternal and paternal (parental) acne did not show additive effects on acne severity risk (Table 3). However, having a mother, a sibling, or at least one parent/sibling with acne was not significantly associated with increased odds of higher acne severity or scarring (data not shown).

A few lifestyle factors and dietary habits were also associated with more severe acne relative to milder acne. Pre- 
Table 1. Demographic characteristics of acne cases and controls and prevalence of severity and scarring grades among acne cases

\begin{tabular}{|c|c|c|}
\hline Variable & $\begin{array}{l}\text { Case } \\
(n=2,090)\end{array}$ & $\begin{array}{l}\text { Control } \\
(n=1,798)\end{array}$ \\
\hline \multicolumn{3}{|l|}{ Gender } \\
\hline Male & $929(44.4)$ & $813(45.2)$ \\
\hline Female & $1,156(55.3)$ & $982(54.6)$ \\
\hline Not stated & $5(0.2)$ & $3(0.2)$ \\
\hline \multicolumn{3}{|l|}{ Age } \\
\hline$>24$ years & $278(13.3)$ & $237(13.2)$ \\
\hline $20-24$ years & $1,493(71.4)$ & $1,253(69.7)$ \\
\hline$\leq 19$ years & $313(15.0)$ & $304(16.9)$ \\
\hline Not stated & $6(0.3)$ & $4(0.2)$ \\
\hline \multicolumn{3}{|c|}{ Family monthly household income } \\
\hline$<2,000$ SGD & $362(17.3)$ & $321(17.9)$ \\
\hline $2,000-3,999$ SGD & $684(32.7)$ & $564(31.4)$ \\
\hline $4,000-5,999$ SGD & $421(20.1)$ & $349(19.4)$ \\
\hline$>6,000$ SGD & $569(27.2)$ & $509(28.3)$ \\
\hline Not stated & $54(2.6)$ & $55(3.1)$ \\
\hline \multicolumn{3}{|l|}{ Acne severity grades $(n=991)$} \\
\hline Nil (no current acne) & $76(7.7)$ & \\
\hline Mild & $741(74.8)$ & \\
\hline Moderate & $171(17.3)$ & \\
\hline Severe & $3(0.3)$ & \\
\hline \multicolumn{3}{|l|}{ Acne scarring grades $(n=988)$} \\
\hline Grade 0 (no current scars) & $382(38.7)$ & \\
\hline Grade 1 & $353(35.7)$ & \\
\hline Grade 2 & $176(17.8)$ & \\
\hline Grade 3 & $74(7.5)$ & \\
\hline Grade 4 & $3(0.3)$ & \\
\hline
\end{tabular}

Values are frequencies (\%).

disposing factors for moderate-severe acne include individuals living in households with one smoker, relative to individuals living in non-smoking households; however, this association was abolished after controlling for confounding factors (Table 3). None of the other smoking variables studied, including smoking status, passive smoking, parental smoking, paternal or maternal smoking, were significantly associated with acne severity (data not shown). In addition, a higher predisposition for moderate-severe acne was noted among alcohol non-drinkers relative to alcohol drinkers (Table 3). After adjusting for familial history, the association between drinking status and acne severity remained significant (adjusted OR $=1.579,95 \% \mathrm{CI}$ : $1.049-2.376, p=0.029$ ), suggesting that drinking status is an independent risk factor for more severe acne relative to milder acne, over and above familial history. In addition, significant associations between milk intake and acne severity, and between butter intake and acne scarring were noted. Frequent milk intake was associated with a protec- tive effect for moderate/severe acne relative to mild acne, while frequent butter intake was associated with a detrimental effect for grade $3 / 4$ acne relative to grade $1 / 2$ acne (Table 3). The latter relationship remained significant after adjusting for familial history (adjusted $\mathrm{OR}=3.451,95 \% \mathrm{CI}$ : $1.438-8.285, p=0.006$ ), suggesting that butter consumption was associated with an increased risk for more severe scarring independent of genetic factors.

\section{Discussion}

Acne is a common skin disease, with high prevalence rates in most countries. The estimated acne prevalence of $53.8 \%$ among Singapore Chinese was similar to the acne prevalence estimates of 51.3\% [12] and 53.5\% [13] obtained in similar studies conducted in China. As there is no consensus on the criteria to grade acne severity, it is difficult to directly compare the results of studies that utilise different severity grading systems [2]. Among our Singapore Chinese subjects, the combined prevalence of moderate and severe acne was $17.6 \%$, way lower than a previous Singaporean study among adolescents $\leq 19$ years $(48.6 \%)$ [10].

Out of all the evaluated factors, positive familial history (either in parents and/or siblings) strongly predisposes an individual to the presence of acne, consistent with our recent meta-analysis (pooled OR of 2.91, 95\% CI: 2.58-3.28; familial history in parents with reference to no familial history in parents) [9] and others [14]. However, the association between familial history and acne severity is unclear; some studies reported a higher prevalence of severe acne grade in those with a positive familial history of acne $[15,16]$, while others reported no significant association [17-19]. In this study, positive paternal/parental and parental/sibling family histories were significantly associated with higher acne severity and scarring, respectively.

Gender and age are two sociodemographic factors affecting acne severity and scarring, but not acne presentation. The 2010 Global Burden of Disease Study [20] and Lynn et al. [21] favoured females as the predisposing gender for acne presentation; however, we reported that male gender is associated with only a slight increase in acne presentation risk (pooled OR $=1.07,95 \%$ CI: 0.42-2.71 [9]). Consistently, we found that being a male poses no significant increase in risk of presenting with acne compared to females, as seen in other studies too [17, 22, 23]. Nevertheless, we found that moderate/severe severity and grade $3 / 4$ scarring was more commonly observed among males compared to females, similar with the studies by Aksu et al. [17] and Kaminsky et al. [19] for acne severity, and by Layton et 
Table 2. Association of selected familial history, comorbidities, and lifestyle factors with acne presentation

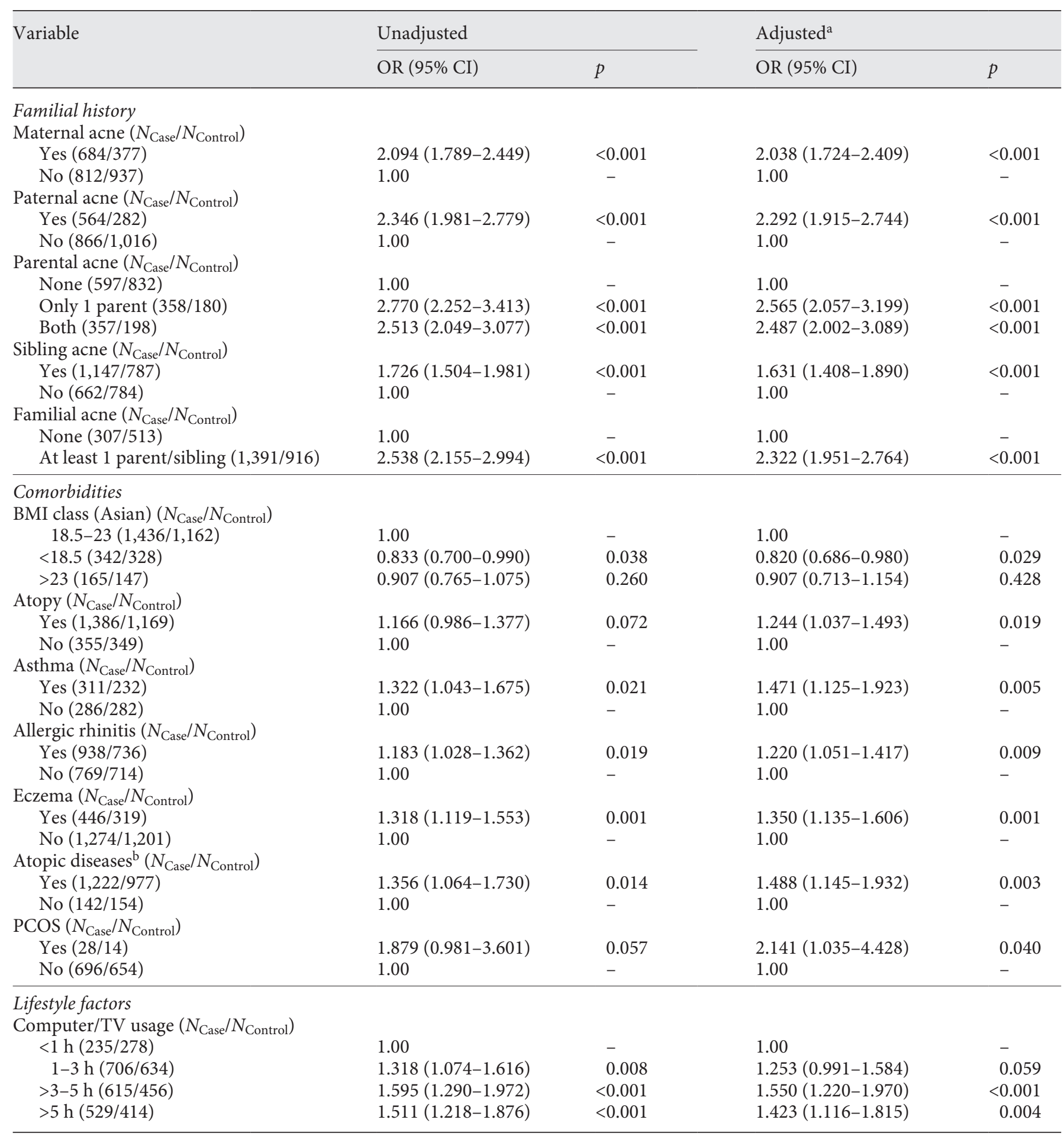

Values are odds ratio (95\% CI). ${ }^{\text {a }}$ Adjusted for age, gender, family monthly household income, BMI, smoking status, alcohol drinking habit, and physical activity. ${ }^{\mathrm{b}}$ Atopic diseases include allergic rhinitis, asthma, and eczema. PCOS, polycystic ovarian syndrome. 


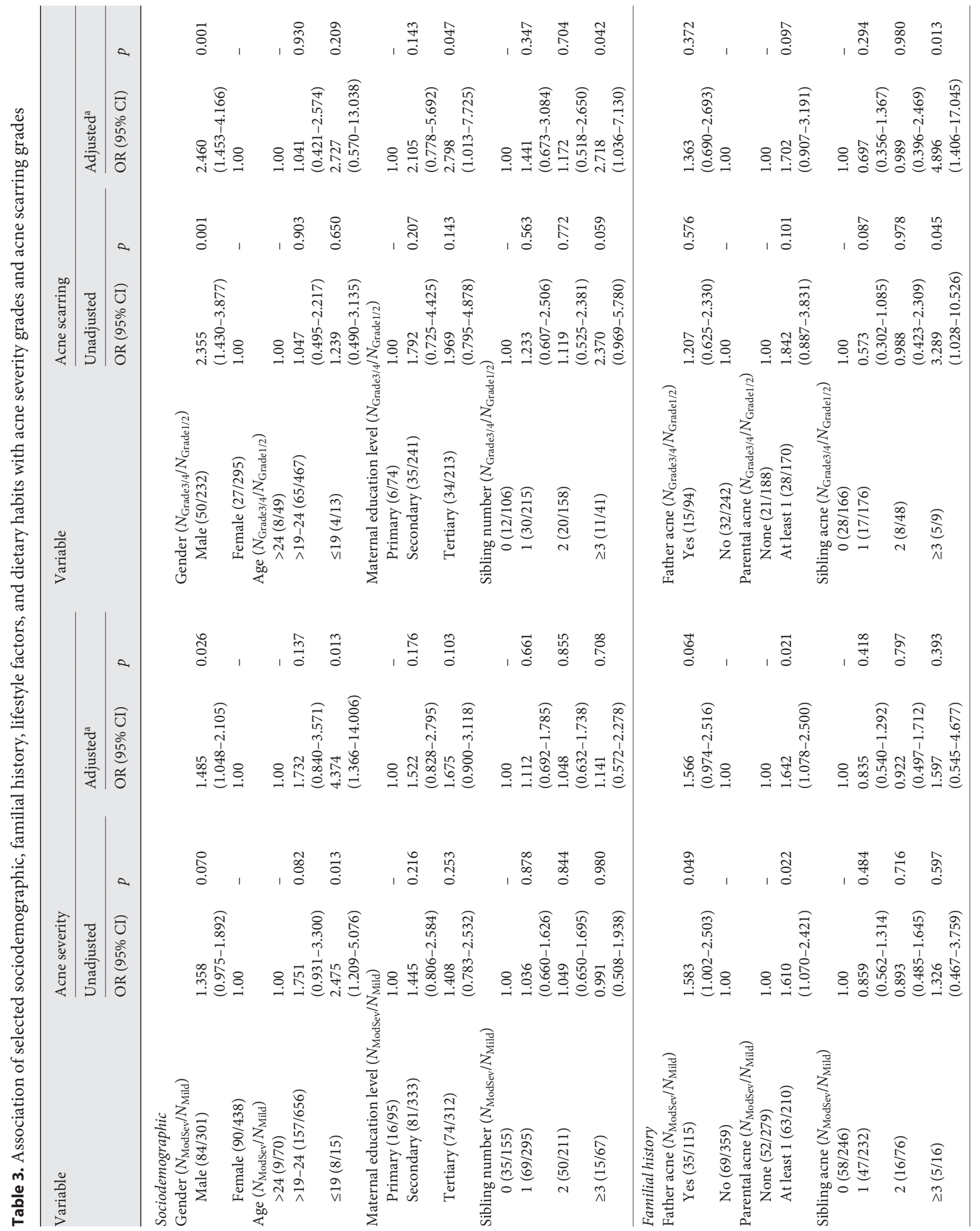




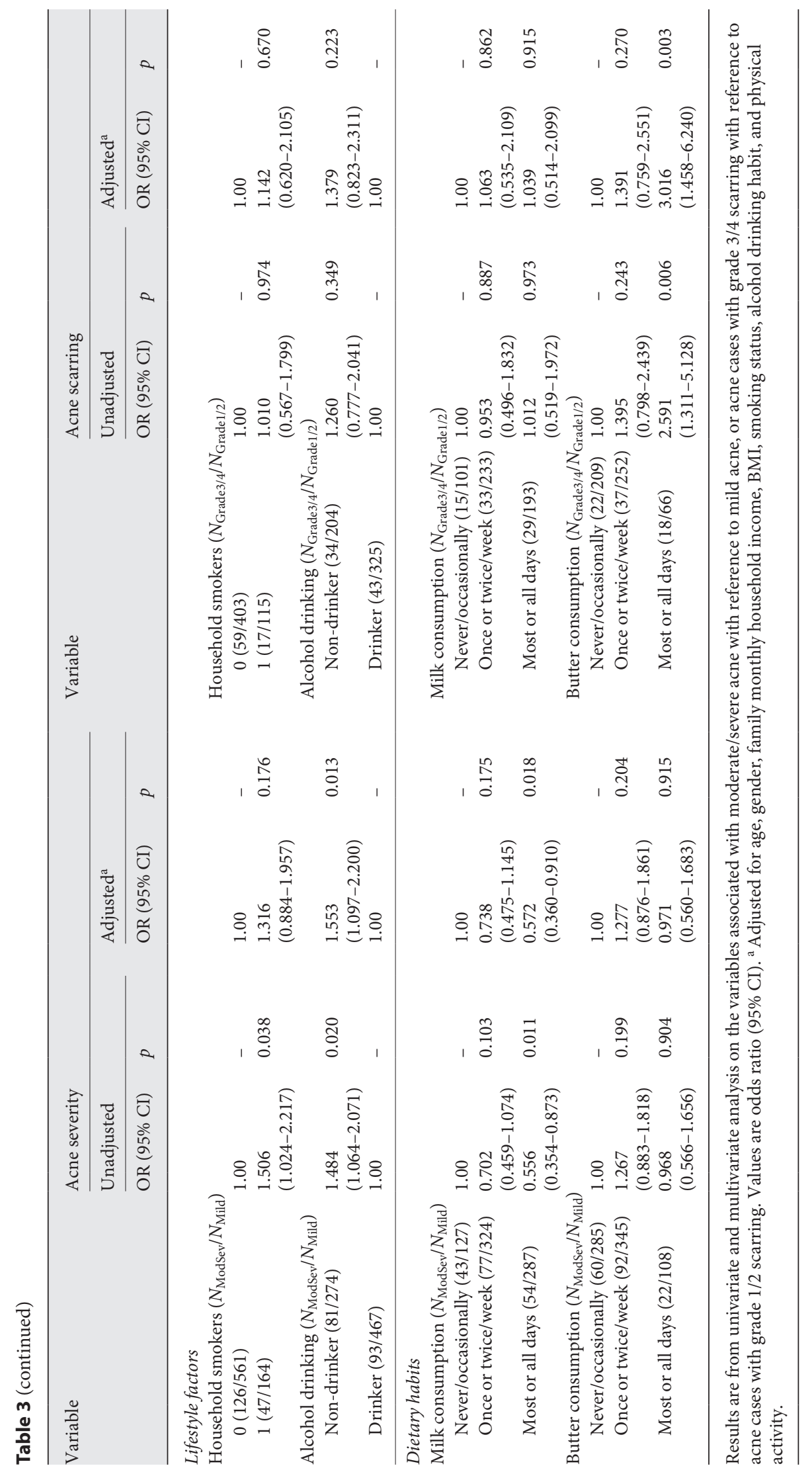


al. [24] for acne scarring. A higher prevalence of moderate/ severe acne was noted among individuals aged $<19$ years compared to those $>24$ years, consistent with a study which reported that the prevalence of more severe forms of acne decreased with age after 18 , while the prevalence of milder forms of acne increased with age until the early thirties [25].

With reference to BMI, consistent with previous findings [26], a lower prevalence of acne in underweight individuals relative to individuals of a healthy weight was observed. In addition, while the result did not reach statistical significance, a trend towards lower odds of acne in overweight individuals relative to individuals with a healthy weight was observed. This contrasts with the findings of previous studies that reported higher acne prevalence in overweight individuals [16-18, 22, 26, 27]. We initially thought that this observation could be due to the use of international BMI categories which may not be appropriate for an Asian population [28]. However, a similar trend of lower odds of acne in overweight individuals was still observed after using the appropriate BMI categories. Furthermore, a sensitivity analysis conducted using BMI as a continuous variable showed no significant pattern in the ROC curve (data not presented).

In this study, acne presentation was also associated with several comorbidities, including atopy, asthma, allergic rhinitis, eczema, atopic diseases, and PCOS. To our knowledge, scarce studies have investigated atopic diseases as comorbidities of acne; for example, Silverberg and Silverberg [29] reported a significant association of severe acne with asthma, but not respiratory allergies. In contrast, a study reported that eczema was less commonly observed among acne cases, and suggested that differences in sebum levels between acne cases and controls may be responsible for this observation [30]. Finally, a study reported that PCOS is more common in women with acne patients compared to the overall population $[31,32]$.

Out of the evaluated lifestyle factors, computer/TV usage had significant association with acne presentation, while presence of household smokers and alcohol consumption were significantly associated with acne severity extent. Computer/TV usage was used as an indication of a sedentary lifestyle; thus, this finding suggests that acne is more common among those with more sedentary lifestyles. A previous study also reported a lower risk of acne in those who used the computer for under $2 \mathrm{~h}$ per day relative to those with higher computer usage [12]. The influence of smoking status on acne presentation and severity is controversial, with inconclusive evidence on whether smoking is a protective or risk factor [1]. Rombouts et al. [33] observed that smoking was linked to decreased acne risk in girls, while smoking was found to be a risk factor for acne [18] and severe acne occurred more frequently among smokers [34]. Studies also considered smoking duration and number of cigarettes smoked - one study observed a significant dose-dependent relationship between acne severity and the number of cigarettes smoked per day [35], another did not [33]. The complex way in which smoking influences the pathogenesis of acne including inflammation, wound healing, and immune responses [33] may contribute, in part, to this inconclusive evidence. A higher risk of moderate-severe acne was also observed in alcohol non-drinkers relative to drinkers, and this significance remained after correcting for familial history, suggesting that the relationship between alcohol consumption and acne severity is independent of familial history. This finding is inconsistent with previous studies that reported no significant relationship between acne severity and alcohol consumption or that suggested that alcohol consumption may worsen acne [33, 34].

The potential link between diet and acne presentation has been widely debated, with some studies finding no significant diet-acne link, while others reporting that the intake of certain foods is associated with acne presentation $[9,36]$. A previous meta-analysis suggested that milk and dairy consumption in general is a potential risk factor for acne [37]. Similarly, a high glycaemic load was suggested to increase the risk for acne [38], which could be attributed partly to the IGF1/FoxO1/mTORC1 signalling pathway. In contrast to these reports, no significant association was found between consumption of dairy products (milk, butter) or high glycaemic index foods (rice, cereals, potatoes) and acne presentation. To support this, sensitivity analysis in a meta-analysis according to the Asian continent showed that dairy consumption was not associated with acne (pooled OR: 1.41, CI: 0.95-2.12) [37], while a large study involving 20,416 Danish adults also found no significant association [39]. However, we did find that frequent milk consumption was associated with a protective effect for moderate-severe acne relative to mild acne, while frequent butter consumption seemed to have a detrimental effect on acne scarring extent. The reason why milk-acne association goes in the opposite direction compared to previous studies could be due to ethnic differences in eating habits, and dairy source differences used in assessing this eating habit (we used the broad term "milk" vs. varieties of dairy products - milk/ cheese/yogurt, cow/goat, whole/full-fat/low-fat/skim, lactose-free products in others). Other evaluated food products/groups had no significant effect on acne presentation, severity, and scarring in this study. The influence 
of these food products/groups, particularly intake of high fat, fish/seafood, fruits and vegetables, and chocolate, has been comprehensively reviewed by us recently [9].

We acknowledge a few limitations in our study. Firstly, as the study subjects were NUS Chinese students and staff, the findings of this study could not be extrapolated to the multi-ethnic Singapore population. Nevertheless, our subjects are still representative enough of the Singapore Chinese population as they came from all parts of Singapore, as assessed by the diversity of the postal codes surveyed in the questionnaire. Next, the three-level food frequency questionnaire used in this study has limited capability to quantitatively evaluate the intake amount of each food type/group, and therefore might be responsible for the discrepancy of findings with regard to dairy product consumption (like milk and butter) and acne risk in other studies. More frequency levels, more commonly consumed food types, or even a repeated 3-day food diary (two weekdays and one weekend) could be adopted in the future.

In conclusion, positive familial history is a strong predisposing factor in determining acne presentation, severity, and scarring. Demographic factors (gender, age) and sedentary lifestyle (increased computer/TV usage) influence acne presentation, while dietary habits (milk and butter consumption) influence acne severity and scarring. The predisposing factors revealed in this study can help researchers and clinicians to understand the epidemiology of acne, especially in the Singapore population. In addition, the findings can guide future research on risk factors with the hope of better understanding the pathophysiology of acne and developing effective interventions especially targeting modifiable risk factors like lifestyle factors and dietary habits.

\section{Key Message}

Positive familial history is a strong predisposing factor in determining acne presentation, severity, and scarring.

\section{Acknowledgement}

We would like to thank all participants and their family members for being willing to participate in this study.

\section{Statement of Ethics}

The National University of Singapore Institutional Review Board (IRB) reviewed and approved the study protocol (IRB numbers: NUS IRB-13-075, NUS IRBH-18-036). All participants (or

parents/guardians for those below 21 years) signed informed consent forms, and the study was conducted in accordance with the Declaration of Helsinki.

\section{Conflict of Interest Statement}

F.T.C reports grants from Singapore Ministry of Education Academic Research Fund, Singapore Immunology Network, National Medical Research Council (NMRC) (Singapore), Biomedical Research Council (BMRC) (Singapore), and the Agency for Science Technology and Research (A*STAR) (Singapore), during the conduct of the study; and consulting fees from Sime Darby Technology Centre; First Resources Ltd; Genting Plantation, and Olam International, outside the submitted work.

\section{Funding Sources}

F.T.C. has received research support from the Singapore Ministry of Education Academic Research Fund, Singapore Immunology Network, National Medical Research Council (NMRC) (Singapore), Biomedical Research Council (BMRC) (Singapore), and the Agency for Science Technology and Research (A*STAR) (Singapore); grant numbers: N-154-000-038-001; R-154-000-404-112; R-154-000-553-112; R-154-000-565-112; R-154-000-630-112; R154-000-A08-592; R-154-000-A27-597; BMRC/01/1/21/18/077; BMRC/04/1/21/19/315; SIgN-06-006; SIgN-08-020; NMRC/ $1150 / 2008$, and $H 17 / 01 / a 0 / 008$. The funding agencies had no role in the study design, data collection and analysis, decision to publish, or preparation of the manuscript.

\section{Author Contributions}

F.T.C. conceived and supervised the current study. A.H.S.H and Y.-H.S. conducted the literature review process, analysed the data for the manuscript, and wrote the manuscript. Y.-H.S., Y.Y.S., and Y.T.N. recruited participants for the study, processed the questionnaires, and analysed the questionnaire data. All authors reviewed and approved the manuscript.

\section{References}

vulgaris. $\mathrm{Br}$ J Dermatol. 2013 Mar; $168(3)$ $474-85$.

2 Williams HC, Dellavalle RP, Garner S. Acne vulgaris. Lancet. 2012 Jan;379(9813):361-72.

3 Mahto A. Acne vulgaris. Medicine. 2017 Jun; 45(6):386-9.

4 Fabbrocini G, Annunziata MC, D’Arco V, De Vita V, Lodi G, Mauriello MC, et al. Acne Scars: Pathogenesis, Classification and Treatment. Dermatol Res Pract. 2010;2010: 893080-13.

5 Jacob CI, Dover JS, Kaminer MS. Acne scarring: A classification system and review of treatment options. J Am Acad Dermatol. 2001 Jul;45(1):109-17. 
6 Goodman GJ, Baron JA. Postacne Scarring: A Qualitative Global Scarring Grading System. Dermatol Surg. 2006 Dec;32(12):1458-66.

7 Goodman GJ, Baron JA. Postacne scarring-a quantitative global scarring grading system. J Cosmet Dermatol. 2006 Mar;5(1):4852.

8 Dreno B, Khammari A, Orain N, Noray C, Mérial-Kieny C, Méry S, et al. ECCA Grading Scale: An Original Validated Acne Scar Grading Scale for Clinical Practice in Dermatology. Dermatology. 2007;214(1):46-51.

9 Heng AHS, Chew FT. Systematic review of the epidemiology of acne vulgaris. Sci Rep. 2020 Dec;10(1):5754.

10 Tan H-H, Tan AWH, Barkham T, Yan X-Y, Zhu M. Community-based study of acne vulgaris in adolescents in Singapore. Br J Dermatol. 2007 Sep; 157(3):547-51.

11 Yosipovitch G, Tang M, Dawn A, Chen M, Goh C, Huak Y, et al. Study of Psychological Stress, Sebum Production and Acne Vulgaris in Adolescents. Acta Derm Venereol. 2007; 87(2):135-9.

12 Wei B, Pang Y, Zhu H, Qu L, Xiao T, Wei $\mathrm{H}-\mathrm{C}$, et al. The epidemiology of adolescent acne in North East China. J Eur Acad Dermatol Venereol. 2010;24(8):953-7.

13 Wu T-Q, Mei S-Q, Zhang J-X, Gong L-F, Wu F-J, Wu W-H, et al. Prevalence and risk factors of facial acne vulgaris among Chinese adolescents. Int J Adolesc Med Health. 2007 Oct;19(4):407-12.

14 Dreno B, Poli F. Epidemiology of Acne. Dermatology. 2003;206(1):7-10.

15 Zahra Ghodsi S, Orawa H, Zouboulis CC Prevalence, Severity, and Severity Risk Factors of Acne in High School Pupils: A Community-Based Study. J Invest Dermatol. 2009 Sep;129(9):2136-41.

16 Karciauskiene J, Valiukeviciene S, Gollnick $\mathrm{H}$, Stang A. The prevalence and risk factors of adolescent acne among schoolchildren in Lithuania: a cross-sectional study. J Eur Acad Dermatol Venereol. 2014 Jun;28(6):733-40.

17 Aksu AE, Metintas S, Saracoglu ZN, Gurel G, Sabuncu I, Arikan I, et al. Acne: prevalence and relationship with dietary habits in Eskisehir, Turkey: Acne prevalence and dietary habits. J Eur Acad Dermatol Venereol. 2012 Dec; 26(12):1503-9.
18 Al Hussein SM, Al Hussein H, Vari CE, Todoran N, Al Hussein H, Ciurba A, et al. Diet, Smoking and Family History as Potential Risk Factors in Acne Vulgaris - a Community-Based Study. Acta Medica Marisiensis. 2016 Jun 1;62(2):173-81.

19 Kaminsky A, FlorezญWhite M, Bagatin E, Arias MI. the Iberian Latin American Acne Studies Group (GILEA - Grupo Ibero-Latinoamericano de Estudio del Acne). Large prospective study on adult acne in Latin America and the Iberian Peninsula: risk factors, demographics, and clinical characteristics. Int J Dermatol. 2019 Nov;58(11):127782.

20 Vos T, Flaxman AD, Naghavi M, Lozano R, Michaud C, Ezzati M, et al. Years lived with disability (YLDs) for 1160 sequelae of 289 diseases and injuries 1990-2010: a systematic analysis for the Global Burden of Disease Study 2010. Lancet. 2012 Dec;380(9859): 2163-96.

21 Lynn D, Umari T, Dellavalle R, Dunnick C. The epidemiology of acne vulgaris in late adolescence. Adolesc Health Med Ther. 2016 Jan; 7:13-25.

22 Park SY, Kwon HH, Min S, Yoon JY, Suh DH Epidemiology and risk factors of childhood acne in Korea: a cross-sectional community based study. Clin Exp Dermatol. 2015 Dec; 40(8):844-50.

23 Wolkenstein P, Machovcová A, Szepietowski JC, Tennstedt D, Veraldi S, Delarue A. Acne prevalence and associations with lifestyle: a cross-sectional online survey of adolescents/ young adults in 7 European countries. J Eur Acad Dermatol Venereol. 2018 Feb;32(2): 298-306.

24 Layton AM, Henderson CA, Cunliffe WJ. A clinical evaluation of acne scarring and its incidence. Clin Exp Dermatol. 1994 Jul;19(4): 303-8.

25 Cunliffe WJ, Gould DJ. Prevalence of facial acne vulgaris in late adolescence and in adults. Br Med J. 1979 Apr 28;1(6171):1109-10.

26 Hogewoning AA, Koelemij I, Amoah AS, Bouwes Bavinck JN, Aryeetey Y, Hartgers F, et al. Prevalence and risk factors of inflammatory acne vulgaris in rural and urban Ghanaian schoolchildren. Br J Dermatol. 2009 Aug; 161(2):475-7.

27 Lu L, Lai H, Pan Z, Wu Z, Chen W, Ju Q. Obese/overweight and the risk of acne vulgaris in Chinese adolescents and young adults. Hong Kong J Dermatolology Venereol. 2017; 25:5-12.
28 WHO Expert Consultation. Appropriate body-mass index for Asian populations and its implications for policy and intervention strategies. Lancet. 2004 Jan 10;363(9403): 157-63.

29 Silverberg JI, Silverberg NB. Epidemiology and extracutaneous comorbidities of severe acne in adolescence: a U.S. population-based study. Br J Dermatol. 2014 May;170(5):113642.

30 Liddell K. A familial study of acne and eczema. Br J Dermatol. 1976 Jun;94(6):633-7.

31 Mehta-AmbalalClinical S. Biochemical, and Hormonal Associations in Female Patients with Acne: A Study and Literature Review. J Clin Aesthetic Dermatol. 2017 Oct;10(10): $18-24$.

32 Timpatanapong P, Rojanasakul A. Hormonal Profiles and Prevalence of Polycystic Ovary Syndrome in Women with Acne. J Dermatol. 1997;24(4):223-9.

33 Rombouts S, Nijsten T, Lambert J. Cigarette smoking and acne in adolescents: results from a cross-sectional study. J Eur Acad Dermatol Venereol. 2007 Mar;21(3):326-33.

34 Karadağ AS, Balta İ, Saricaoğlu H, Kiliç S, Kelekçi KH, Yildirim M, et al. The effect of personal, familial, and environmental characteristics on acne vulgaris: a prospective, multicenter, case controlled study. G Ital Dermatol Venereol. 2019 Mar;154(2):177-85.

35 Schafer T, Nienhaus A, Vieluf D, Berger J, Ring J. Epidemiology of acne in the general population: the risk of smoking. Br J Dermatol. 2001 Jul;145(1):100-4.

36 Claudel JP, Auffret N, Leccia MT, Poli F, Dréno B. Acne and nutrition: hypotheses, myths and facts. J Eur Acad Dermatol Venereol. 2018 Oct;32(10):1631-7.

37 Juhl C, Bergholdt H, Miller I, Jemec G, Kanters J, Ellervik C. Dairy Intake and Acne Vulgaris: A Systematic Review and Meta-Analysis of 78,529 Children, Adolescents, and Young Adults. Nutrients. 2018 Aug 9;10(8): 1049.

38 Melnik BC, Zouboulis CC. Potential role of FoxO1 and mTORC1 in the pathogenesis of Western diet-induced acne. Exp Dermatol. 2013 May;22(5):311-5.

39 Juhl CR, Bergholdt HKM, Miller IM, Jemec GBE, Kanters JK, Ellerviket C. Lactase Persistence, Milk Intake, and Adult Acne: A Mendelian Randomization Study of 20,416 Danish Adults. Nutrients. 2018 Aug 8;10(8):1041. 